\title{
Family Relations and School Experiences in Criminal Recidivists with a Comorbid Substance Use Problem
}

\author{
Erik Søndenaa (Corresponding author) \\ St. Olavs University Hospital HF, Forensic Department Brøset \\ PO 1803, Lade, 7440 Trondheim, Norway \\ E-mail: erik.sondenaa@ntnu.no \\ Bjørn Arnesen \\ Central Norwegian Resource Center \\ Hans Barliens vei 6, 7040 Trondheim, Norway \\ E-mail: bjorn@mka.no \\ Torill Karlsen \\ Trondheim municipality, Gjengangerteamet \\ 7004 Trondheim, Norway \\ Jim Aage Nøttestad \\ St. Olavs University Hospital HF, Forensic Department Brøset \\ PO 1803, Lade, 7440 Trondheim, Norway \\ Arne Kvithammer \\ Sentrum Politistasjon \\ PO 2475, Sluppen, 7005, Trondheim, Norway \\ Roger Almvik \\ St. Olavs University Hospital HF, Forensic Department Brøset \\ PO 1803, Lade, 7440 Trondheim, Norway
}

Received: March 21, 2012

Accepted: March 27, 2012

Published: May 1, 2012

doi:10.5539/jedp.v2n1p137

URL: http://dx.doi.org/10.5539/jedp.v2n1p137

\begin{abstract}
In making progress to the number of recidivist offenders, different service agencies established a cooperative aiming to offer more complete service. Contact groups consisting of police officers, prison officers and local community social workers collaborated on a magnitude of targets. A survey was conducted to study the social networks, educational background, welfare problems and self management skills among 35 recidivists with a comorbid substance use problem. Results showed fewer welfare problems and better self management in recividists who had more years in the educational system and in those with a good relation to their brother. The results argue for more inclusive educational services and the use of certain family members as a resource in the public collaboration to prevent further offences.
\end{abstract}

Keywords: Recidivist offenders, Family relations, School experiences, Resilience 


\section{Introduction and Background}

To fulfill and succeed in preventive work, the knowledge of risk-promoting and protective factors are crucial. Previous research reports an association between social ties within the family, school and circle of friends, and later problems with substance abuse and criminality (Farrington, 1998; Hawkins, Catalano, \& Miller, 1992). Early experience with available social support and help from significant others, ability to seek help and comfort, and efficient handling of stress and strain, have all been identified as protective factors (Olsen \& Traavik, 2010).

\subsection{The impact of Close Relations}

Social support can be defined as the extent of instrumental and emotional support from close relationships, social networking and community (Hochstetler, DeLisi, \& Pratt, 2010). A neighbour, friend or a family member who volunteers to look after the children, take in mail, watering the flowers, give advice and assistance, are all examples of social support. Social support is also exchanged formally and informally through schools, communities, public services and correctional services. According to Cullen (1994), social support is of theoretical significance in criminology because it serves as a protective factor for victims of crime and is also crucial for the criminal rehabilitation. In correctional services, social support resources and safety nets help to keep released prisoners away from committing further crime. Cullen and colleagues have through several studies indicated that when social support is provided through training in interpersonal skills and through counselling with health and social care services, has led to declined in reoffending behaviour (Colvin, Cullen, \& Vander Ven, 2002; Cullen, Wright, \& Chamlin, 1999). The potentially harmful consequences of a prison sentence can thus be balanced with the provision of social support. Social development theory considers the family as a basic socializing arena, and that the family's direct influence decreases in late adolescence (Bronfenbrenner, 1986). This understanding has thus supported preventive measures in the family with a focus on childhood and early adolescence (Farrington \& Welsh, 2005). Recent Norwegian registry research found an increased risk of being charged with offences among the children of young unmarried mothers, as well as those who have experienced divorce or where the mother has died (Galloway \& Pudney, 2011).

\subsection{Recidivist Offender}

Recent Norwegian research has shown that male recidivist adults are to a much greater extent than other offenders are influenced by the problems of childhood, and that their social and economic problems are more complex (Kjelsberg \& Friestad, 2008). The research showed that the chance of repeated incarceration increased by 3.6 times if the person as a child had experienced that one of one's family members had been imprisoned. These men's difficulties in coping with life in many areas means that it will be necessary to address many aspects to obtain changes. An exclusive focus on drug treatment does not necessarily have any effect on the housing situation, meaningful life-content, or social relationships (Hansen \& Friestad, 2004). Research has documented the apparent link between living in a partnership and reduced relapse into crime (Farrington \& West, 1995; Warr, 1998). The same applies for relapse to substance abuse (Duncan, Wilkerson, \& England, 2006). Family and friends' impact on lessening recidivism has recently been linked to studies of "social capital", with a focus on mobilizing the potential of such capital for repeat offenders (Mills \& Codd, 2008).

\subsection{Research Questions}

1) Do we find any family relations which have significance for preventing drug abuse, crime and/or everyday problems?

2) What school experiences can prevent substance abuse, crime and/or everyday problems?

\section{Method}

\subsection{Sample}

All participants were highly ranked on police lists of criminal drug abusers. An explicit self-motivation to break the crime-cycle and terminate substance abuse, previous drug and crime-free periods, a social network outside of the criminal community, vocational and work experience and interest in leisure activities were also criteria for taking part in the study (Elvegård, 2010). Interdisciplinary cooperation and exchange of information between the professionals was also presupposed (Arnesen, 2010). A total number of 50 people who filled the criteria were asked to participate and 35 people (70\%) gave their consent.

\subsection{Interview}

Based on research on resilience (Arnesen, 1994; Ducan, 1989, Olsen \& Traavik, 2010) a structured interview form was developed to clarify the protective factors, resilience and risk factors among the participants. A multidisciplinary team prepared the interview guide, based on 67 questions grouped according to the following 
themes: 1). Demographic data, 2). Experiences with: family, school, substance abuse, health and crime, and 3). Self-efficacy. Information on the family relationship was gathered about parents, siblings, partners and their own children. Information was obtained about the number of completed school years, suspensions from school, grades and positive experiences related to education.

\subsection{Procedure}

Professionals from police, prison and local social services conducted the interviews. The duration of each interview ranged from 20 minutes to two hours. Twelve of the informants were serving a sentence at the time of interview. All respondents gave informed consent to participate.

\subsection{Data Analysis}

The Statistical Package for the Social Sciences (SPSS) version 15 was used to analyze the data. Besides descriptive statistics, non-parametric tests were used because the variables were rated on nominal and ordinal level.

\section{Results}

Information on age was divided into intervals of five years. The sample was mainly located in the age groups 26-40 years. Only one person in the sample was over 45 years. The gender distribution was 32 men and 3 women. The people were ethnic Norwegians except one foreigner.

\subsection{Arrests and Convictions}

The number of apprehensions or arrests by the police was generally high, only $4(11 \%)$ reported the number of apprehensions beneath 30 occasions. The number of imprisonments was for the majority (57\%) less than 10 sentences. Figure 1 provides an overview of arrests and convictions.

\section{Insert Figure 1 Here}

\subsection{Family Relations and Self Efficacy}

Two different approaches to family relationships were studied. 1. The familiar history of substance abuse, health problems, violence/aggression and/or crime. 2. Relationships with parents, siblings and their own children as described at the time of the interview. Problems in the immediate family were described by 27 people (90\%). Five of the people omitted to answer these questions, while three did not declare this type of problem. Substance abuse in the immediate family was dominant and was stated by 19 people $(63 \%)$. The problems seemed highest for alcohol (16 individuals, 53\%), while drug problems were stated by 9 people, $30 \%$. Health problems (mental or physical health) were described by 14 people $(47 \%)$ and included mental health in $7(23 \%)$ and somatic health in $8(27 \%)$. One person described both mental and somatic health problems. Violence / aggression was described by $8(27 \%)$, while criminal offences were described during childhood from $5(17 \%)$. Of those who described substance abuse in their own families, $84 \%$ said that they were drug addicts on the examination date. This was more common than in the sample as a whole $\mathrm{X} 2(1, \mathrm{~N}=35)=4.7, \mathrm{p}=0.03$. Those who described health problems in their own families had fewer close friends than those without such family problems X2 $(1, \mathrm{~N}=35)$ $=4.9, \mathrm{p}=0.03$. People with childhood experiences of domestic violence reported more homelessness as adults than the others X2 $(1, \mathrm{~N}=35)=5.6, \mathrm{p}=0.02$. A total of $32(91 \%)$ still were attached to their own mother, 28 $(80 \%)$ to their father, $22(63 \%)$ to their sister(s) and $27(77 \%)$ to their brother(s). The questions were answered on a scale of one to four where one was not consistent with the person and four were very close agreement with the person. The data was simplified by combining the two most positive and the two most negative response options. Table 1 describes the relationships:

\section{Insert Table 1 Here}

Self efficacy was not found different relating to positive or negative relationship with their father, mother or sister. Relationship with their own brother, on the other hand, was related to several factors. A positive brother relationship was often quoted by people who rated as more healthy $\mathrm{X} 2(1, \mathrm{~N}=27)=5.0, \mathrm{p}=0.03$ and individuals who had received drug treatment, $\mathrm{X} 2(1, \mathrm{~N}=27)=8.0, \mathrm{p}=.012$. It was also indicated that a positive brother relationship was given more frequently in people who were not drug addicts at the interview, as well as in people who had confidential persons to seek. About half of people had their own children $(\mathrm{N}=17)$. These individuals were generally older than those who had no children. Parenthood was more common in those who had been through drug-free periods in the past six months, $\mathrm{X} 2(1, \mathrm{~N}=35)=4.6, \mathrm{p}=.031$. Individuals with own children answered that they were less worried about their health than people without children $\mathrm{X} 2(1, \mathrm{~N}=35)=$ $6.4, \mathrm{p}=.011$. 


\subsection{School Experience and Self Efficacy}

The Norwegian educational system requires at least 10 years basic education, and about $70 \%$ of all adolescents complete at least 13 years (National Statistics, 2009). Eleven persons (31\%) in the present sample had less than 10 years, $20(57 \%)$ had between 10 and 13 years, while only $4(12 \%)$ had more than 13 years. A total of 22 people $(63 \%)$ had been expelled from school on behavioural reasons. Subjective statements about their performance showed that 13 persons (37\%) had achieved poor grades during their last school year, $15(43 \%)$ thought the grades were intermediate, while $7(20 \%)$ thought they were good. Experiences from school were associated with the following eight areas: 1) Positive relation to a teacher, 2) Succeeded in one or more subjects, 3) Good school mates, 4) Positive feedback from peers, 5) Positive feedback from teachers, 6) Positive break activities and 7) Positive school trips. One person had no positive experiences of schooling while the majority reported several factors that had been of positive significance, mean $4.1(\mathrm{SD}=2.1)$. In the further analysis, a distinguish was made between individuals with many (4 or more) positive school experiences and those with few (less than 4) positive experiences. The number of completed school years (length of education) appeared to be significant for a number of factors. Early finishing school was found more frequently in people who had lived in institutional care X2 $(1, \mathrm{~N}=35)=7.7, \mathrm{p}=0.009$, in people with early crime debut $\mathrm{X} 2(1, \mathrm{~N}=35)=7.1, \mathrm{p}=0.01$, in subjects with the most convictions X2 $(1, \mathrm{~N}=35)=4.0, \mathrm{p}=0.046$, and in people with diminished help seeking behaviour X2 $(1, \mathrm{~N}=35)=4.0, \mathrm{p}=0.046$. People reporting a history of expulsion from school had been arrested by police more often than the other X2 $(1, \mathrm{~N}=35)=5.2, \mathrm{p}=.025$. People with many positive experiences of schooling reported less problems with substance abuse X2 $(1, \mathrm{~N}=35)=5.4, \mathrm{p}=.022$.

\subsection{School Experiences and Family Relationships}

Both school experiences and family relationships were related to different aspects of self-efficacy. The relationship between school experiences and family relationships were found for school dropout and growing up conditions with a substance abuse in close family member(s) X2 $(1, \mathrm{~N}=35)=8.7, \mathrm{p}=0.004$. Those who had witnessed crime in their own family referred to their own schooling as less positive than the others $\mathrm{X} 2(1, \mathrm{~N}=35)$ $=6.0, \mathrm{p}=.014$. They had also dropped out of schooling at an earlier level X2 $(1, \mathrm{~N}=35)=4.9, \mathrm{p}=0.05$.

\section{Discussion}

Problems in the family appeared to affect a variety of aspects in people's perceived quality of life. Family background of substance abuse may appear to persist in a more inflexible substance abuse problem. Health problems in this group seems to be socially limiting and experiences with violence in the family can lead to increased problems with future stability. (Kjelsberg \& Friestad, 2008) found that Norwegian recidivists more frequently than the first time prisoners had experienced substance abuse, crime, conflict and abuse in their family. They also found that recidivists had received child welfare services more frequently. Mothers were more positive than the fathers from the recidivists' evaluation of parenthood. The father's tendency to reject their recurring criminal sons, and mothers' patience and forgiveness can possibly explain some of this.

The results indicating the high impact of a positive brother relationship, may have further implications. Such a relation seemed to promote motivation for change and to limit anxiety about their own health. Applying relatives' support and exploring the qualities in a healing brotherhood as this study indicates, have not been highlighted in recent publications, and should be studied in more detail. As one of our participants cited about his brother relationship: "My brother is the finest man I know. He supported me when I was bullied. He was bullied for having a jerk like me as his brother. He never put the blame on me, but supported me as best he could. Still I disappointed him, and scared him when I was pissed." Parenthood will naturally cause problems for criminal recidivists, although the data show several breaks from substance abuse and less self-concerning. Being a parent can contribute to increased motivation to break with the crime, and substance abuse and homelessness are incompatible for the person who wants to fulfil the parental role. School experiences provide evidence that the number of completed school years is more crucial than the retrospective experience of well-being in school. The findings show no difference in perceived satisfaction and the number of completed school years, while early school dropout shows several aspects that may aggravate an already difficult situation. Earlier crime debut, more convictions and a lack of social support may occur more frequently in those with a shorter school career. We found a further reduction in the number of school years in people who have lived in institutional care. This may be a matter of limited schooling priorities in the child welfare authorities, or a diminished motivation from the institutionalized children. However, the significance of staying in school should be promoted. Adaptation and integration into regular school addresses relational skills, and special educational skills in the schools. Placement in a child welfare institution is often dependent on loss of significant and stable relationships, and it is reasonable that the opportunities for successful schooling will increase by more enduring services. The motivation for 
further education is found to be about $50 \%$ of prison inmates in general (Manger, Eikeland, Asbjornsen, \& Langelid, 2006) and strongest among the youngest. Crime and substance abuse in the family during adolescence appears to be most decisive for school drop-out, as well as bad experiences from school. Kjelsberg \& Friestad, (2008) found that recidivists was less educated than the first time detainees in Norway, and associated to other findings, the number of social problems is consistently higher in the former group.

\subsection{Reservations}

This study was based on a selective range of criminal recidivists. The sample is small but significant because of their persistent contact in the criminal justice. One possible source of error from the sample-size, may be that differences are ignored (type 1 error). The results should then mainly indicate the need for further studies. Studies with a deeper focus on the brothers relationship may however provide useful knowledge to improve rehabilitation. Studies about drop-out from school also seem to be advisable on the basis of our findings.

\subsection{Conclusions}

Two findings seem to be of greatest significance in this study. These findings are significant for our understanding of the social capital of criminal recidivists. First, a positive brother relationship has significant potential. The awareness of this relationship can be of importance for improving rehabilitation. Second, the survey reveals the critical importance of education. Preventing drop-out from school may contribute to preventing later drug abuse and crime. Given the extensive need for public services such as criminal recidivists have, the coordination of services should be required. Loss in education and familiar relations as this study emphasized does not cover all the needs to be met. More studies are needed to explore the protective and risk-promoting factors more thoroughly. The basis for a more competent rehabilitation depends on further studies.

\section{Acknowledgements}

The authors would like to thank Adrian Ward for valuable comments and proof reading.

\section{References}

Arnesen, B. (1994). Brudd og håp. 10 ungdommers møte med en korttidsinstitusjon i barnevernet. Trondheim: NTNU.

Arnesen, B. (2010). Et verdig liv. Kartleggingsrapport om gjengagnerkriminelle bosatt $i$ Trondheim kommune 2009-2010. Trondehim: Trondheim kommune.

Bronfenbrenner, U. (1986). Ecology of the family as a context for human development: Research perspectives. Developmental Psychology, 22, 723-742. http://dx.doi.org/10.1037/0012-1649.22.6.723

Colvin, M., Cullen, F. T., \& Vander Ven, T. (2002). Coercion, social support, and crime: An emerging theoretical consensus. Criminology, 40(1), 19-42. http://dx.doi.org/10.1111/j.1745-9125.2002.tb00948.x

Cullen, F. T., Wright, J. P., \& Chamlin, M. B. (1999). Social support and social reform: A progressive crime control agenda. Crime \& Delinquency, 45(2), 188-207. http://dx.doi.org/10.1177/0011128799045002002

Ducan, T. F. (1989). Acting on Acting Out: Variables in the development of resiliency in adolescence. In T. F. Ducan \& R. Coles (Eds.), The child in our times: Studies in the develpoment of resiliency. New York: Brunner/Mazel.

Duncan, G. J., Wilkerson, B., \& England, P. (2006). Cleaning up their act: the effects of marriage and cohabitation on licit and illicit drug use. Demography, 43(4), 691-710. http://dx.doi.org/10.1353/dem.2006.0032

Elvegård, K. (2010). Det er ikke korgutter!: Evaluering av gjengangerprosjektet. Trondheim: NTNU Samfunnsforskning.

Farrington, D. (1998). Predictors, causes, and correlates of male youth violence. In M. Torny \& M. Moore (Eds.), Crime and justice: A review of research: Vol 24. Youth violence. Chicago: University of Chicago Press.

Farrington, D., \& Welsh, B. C. (2005). Randomized experiments in criminology: What have we learned in the last two decades? Journal of Experimental Criminology, 1, 9-38. http://dx.doi.org/10.1007/s11292-004-6460-0

Farrington, D., \& West, D. (1995). Effects of marriage, separation and children on offending by adult males. Current Perspectives on Ageing and the Life Cycle, 4, 249-281.

Galloway, T. A., \& Pudney, S. (2011). Initiation to crime: An analysis of Norwegian register data on five birth cohorts. Oslo: Statistics Norway.

Hansen, I. L. S., \& Friestad, C. (2004, 08.09). Dårlige levekår er en del av gjengangerproblematikken. 
Dagsavisen.

Hawkins, J. D., Catalano, R. F., \& Miller, J. Y. (1992). Risk and Protective Factors for Alcohol and Other Drug Problems in Adolescence and Early Adulthood - Implications for Substance-Abuse Prevention. Psychological Bulletin, 112(1), 64-105. http://dx.doi.org/10.1037/0033-2909.112.1.64

Hochstetler, A., DeLisi, M., \& Pratt, T. C. (2010). Social Support and Feelings of Hostility Among Released Inmates. Crime \& Delinquency, 56(4), 588-607. http://dx.doi.org/10.1177/0011128708319926

Kjelsberg, E., \& Friestad, C. (2008). Social Adversities in First-Time and Repeat Prisoners. International Journal of Social Psychiatry, 54(6), 514-526. http://dx.doi.org/10.1177/0020764008091406

Manger, T., Eikeland, O. J., Asbjørnsen, A., \& Langelid, T. (2006). Educational Intentions among prison inmates. European Journal of Criminal Policy and Research, 12, 35-48. http://dx.doi.org/10.1007/s10610-006-9007-2

Mills, A., \& Codd, H. (2008). Prisoners' families and offender management: Mobilizing social capital. Probation Journal, 55, 9-24. http://dx.doi.org/10.1177/0264550507085675

Olsen, M. I., \& Traavik, K. M. (2010). Resiliens i skolen. Bergen: Fagbokforlaget.

Warr, M. (1998). Life-course Transitions and Desistance from Crime. Criminology, 36, $183-216$. http://dx.doi.org/10.1111/j.1745-9125.1998.tb01246.x

Table 1. The responders evaluation of their familial relationships

\begin{tabular}{|ccc|}
\hline Relation to & Positive & Negative \\
\hline Father $(\mathrm{N}=28)$ & $46 \%$ & $54 \%$ \\
Mother $(\mathrm{N}=32)$ & $78 \%$ & $22 \%$ \\
Sister $(\mathrm{N}=22)$ & $64 \%$ & $36 \%$ \\
Brother $(\mathrm{N}=27)$ & $63 \%$ & $37 \%$ \\
\hline
\end{tabular}

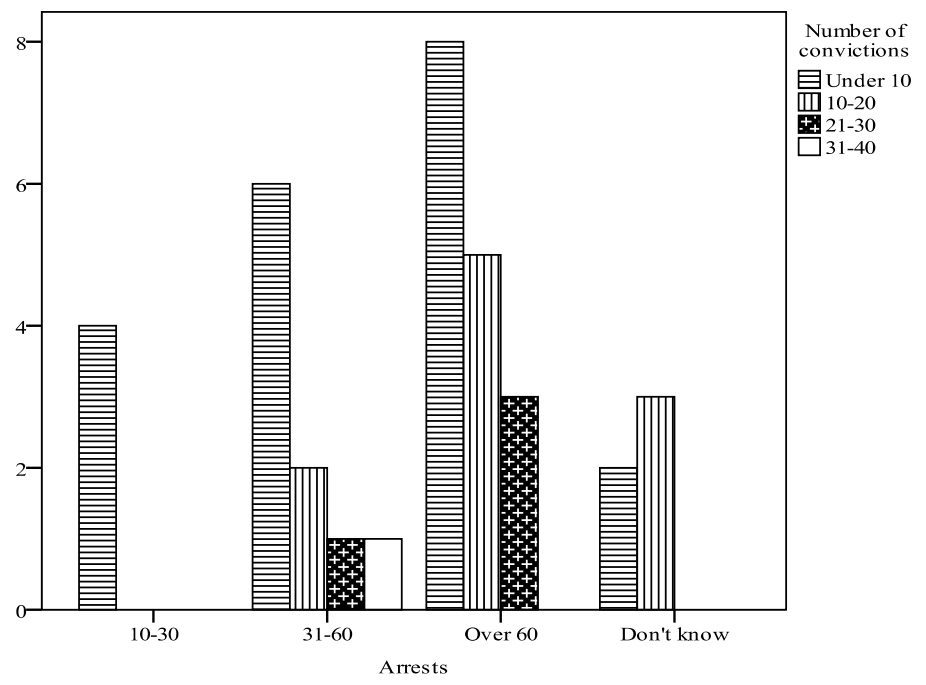

Figure 1. Number of convictions and arrests 